Sir,

\section{Adult ocular leech infestation}

We present a case of adult ocular leech infestation

\section{Case report}

During a trekking expedition to the Borneo jungle, a 28-year-old man presented with a 5 min history of ocular pain after a foreign body hit his right eye while attaching a hammock to a tree. On ophthalmological examination he had intense blepharospasm and a tissue mass attached to the temporal bulbar conjunctiva of his right eye, with surrounding subconjunctival

haemorrhage. The mass was identified as a tiger leech 'Haemadipsa picta' (Figure 1a). This was removed with direct application of cooking salt to the leech and gentle traction with forceps ensuring the head was not left in the wound. The eye was then irrigated with 2 litres of normal saline and chloramphenicol ointment applied to the eye. A patch was placed over the eye and the patient was evacuated on foot for further assessment. The patient's visual acuity remained 6/6 throughout. He sustained a large subconjunctival haemorrhage (Figure $1 b$ ), which resolved completely in 14 days. There was no evidence of scleral perforation and he made a complete recovery.

\section{Comment}

'Leechmania' or the use of medicinal leeches has occurred for over 2500 years. ${ }^{1}$ They play a useful role in modern plastic surgery because of their superb decongestant properties. ${ }^{2}$ In a hospital setting, leeches have been used to drain periorbital and scrotal haematomas, ${ }^{1,3}$ but in these cases the leeches detach from the skin once they have finished their meal. Different types of leeches are grouped according to the different ways they feed. One group (the jawed leeches or Gnatbobdellida) have jaws armed with teeth with which they bite the host. The blood is prevented from clotting by production of a nonenzymatic secretion called hirudin. The land leech commonly encountered by bushwalkers is included in this group. ${ }^{4}$

In a hospital emergency setting, there have only been two reported cases of ocular leech infestation, to the authors' knowledge. ${ }^{5,6}$ A 4-year-old girl in south-west Germany $^{5}$ with Theromyzon tessulatum (duck leech) infestation and a 7-year-old boy in Turkey ${ }^{6}$ with Limnatis nilotica infestation. In these cases both patients reached immediate hospital treatment. The method of extraction involved instilling topical anaesthetic drops and removing the leeches with forceps. In our case, no topical anaesthetic drops were available. In an expedition setting, it is very important to ensure the leech's jaws
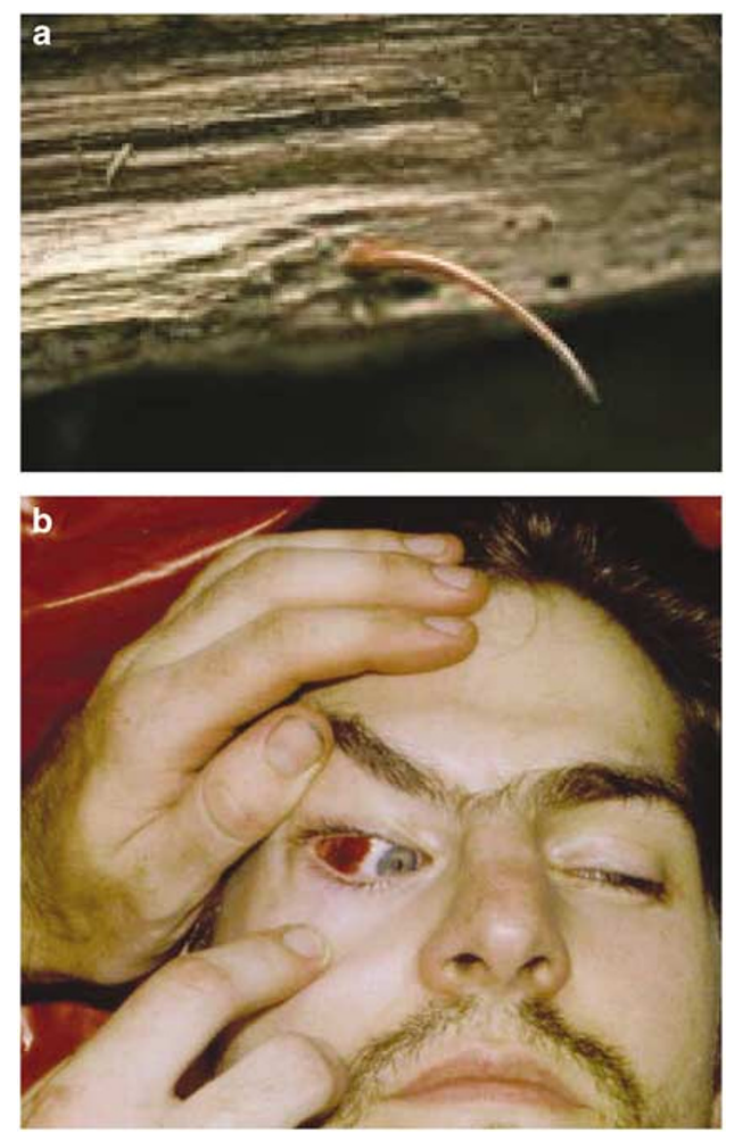

Figure 1 (a) A Tiger Leech. (b) Five minutes post-leech bite.

have detached before removal, as these can detach from the leech during extraction and remain in the wound leading to a source of infection. It is unknown whether there is a specific preparation for the removal of leeches but there is a plethora of tried and tested, but unproven ideas. These include applications of eucalyptus oil, ${ }^{4}$ tropical strength insect repellent (50-100\% DEET), lemon juice, heat from cigarettes, flames from lighters, tiger balm, moist tobacoo, or salt. There are obvious potential dangers of the use of some of these methods close to the eye. In the emergency setting, salt was deemed the least damaging to the eye and was followed by profuse normal saline irrigation. To the authors knowledge, this is the first recorded adult case of ocular leech infestation. If no topical anaesthetic drops are available we conclude that salt is the safest method of leech detachment.

\section{References}

1 Menage MJ, Wright G. Use of leeches in a case of severe periorbital haematoma. Br J Ophthalmol 1991; 75: 755-756.

2 Rao P, Baille FB, Bailey BN. Leechmania in microsurgery. Practioner 1985; 229: 901-903. 
3 Goessl C, Steffen-Wilke K, Miller K. Leech therapy for massive scrotal haematoma following percutaneous transluminal angioplasty. J Urol 1997; 158: 545.

4 http://www.amonline.net.au/factsheets/leeches.htm

5 Auw-Haedrich C, Keim A, Kist M. Conjunctival infestation of a child with Theromyzon tessulatum. Br J Ophthalmol 1998; 82(9): 1093-1094.

6 Alcelik T, Cekic O, Totan Y. Ocular leech infestation in a child. Am J Ophthalmol 1997; 124: 110-112.

\section{G Lewis and A Coombes}

Ophthalmology Department, St Bart's and Royal London Hospital NHS Trust, UK

Correspondence: G Lewis, Department of Ophthalmology,

Addenbrooke's Hospital,

Addenbrooke's, Cambridge,

Cambridge CB1, UK

Tel: + 44 7702747290;

Fax: + 441223373585

E-mail: garethlewis@doctors.org.uk

Eye (2006) 20, 391-392. doi:10.1038/sj.eye.6701862; published online 15 April 2005

Sir,

In vivo confocal microscopy in congenital rubella keratopathy

Systemic manifestations of congenital rubella syndrome (CRS) include ocular complications (88\%), hearing loss (71\%), neurologic deficits (75\%), and cardiac anomalies $(38 \%){ }^{1}$ Recognition of ocular manifestations is important in making the right diagnosis in patients with late presentation or without full-blown systemic involvement. ${ }^{1,2}$ Cataracts, microphthalmia, glaucoma, and 'salt-and-pepper' retinopathy were the major ocular features, while rubella keratopathy is less common which might be the sequel of either associated glaucoma or direct viral cytopathologic effect. $^{2}$ Recent advent of confocal microscopy in delineating corneal pathologies has enchanted in vivo analysis of many corneal diseases at cellular level. ${ }^{3,4}$

\section{Case report}

A 20-year-old Chinese man without remarkable paediatric history except sensorineural deafness presented to us in July 2002 with bilateral blurring of vision. Best-corrected visual acuities for the right and left eyes were 20/200 and $20 / 70$, respectively. Intraocular pressure (IOP) was $12 \mathrm{mmHg}$ in each eye. Slit-lamp examination revealed diffuse corneal guttata with 'beaten-bronze' appearance. A faint haziness at the stroma was noted but neither Haab's striae nor buphthalmos could be seen. The iris, lens, iridocorneal angles, and corneal sensations were intact. Fundus examination revealed bilateral pigmentary retinopathy and a small juxtafoveal choroidal neovascularization membrane in the left eye (Figure 1a and $b$ ). The optic discs and retinal vessels were unremarkable. Small decrement in amplitudes of both scotopic and flicker electroretinogram were noted, suggestive of secondary combined rod and cone involvements. Specular microscopy showed decreased endothelial counts (667 and 712 per square $\mathrm{mm}$ in right and left eyes, respectively). Rubella antibody screening by enzyme immunoassay confirmed positive rubella IgG antibody. The loss of hearing, pigmentary retinopathy in this case has already fulfilled World Health Organization recommended case definition for clinically confirmed CRS despite lack of IgM confirmation or other systemic features. $^{5}$
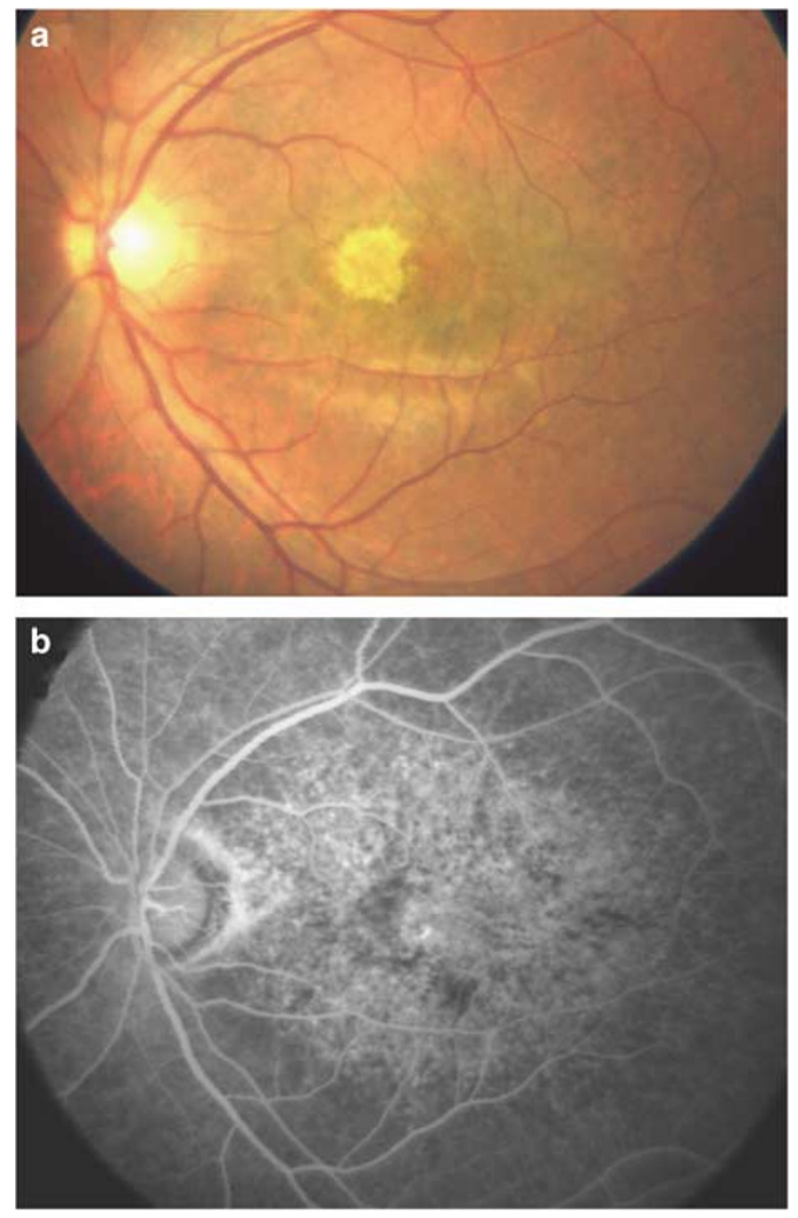

Figure 1 (a) Colour fundus photography of the left eye. It shows a whitish subretinal fibrotic scar at the macula and generalized pigmentary changes at the posterior pole. (b) Fluorescein angiography of the left eye. Hyperfluorescence mottling at the posterior pole is caused by the retinal pigment epithelium atrophy. 